\title{
An Examination of Loading Profiles for Youth Athletes Performing the Hang Power Clean
}

\author{
Kelton D. Mehls' ${ }^{1}$ Sarah C. Martinez ${ }^{2}$, Connor Edwards ${ }^{3}$ \\ Affiliations: 'Duquesne University, Athletic Training Department, Pittsburgh, Pennsylvania, United States, ${ }^{2}$ Georgia State University, Kinesiology \\ and Health Department, Atlanta, Georgia, United States, ${ }^{3}$ Independent Researcher, no affiliation
}

Correspondence: K.D. Mehls, Duquesne University, Faculty for Health Sciences, 600 Forbes Ave, Pittsburgh, Pennsylvania 15828, United States. Email: mehlsk@duq.edu

\begin{abstract}
Weightlifting derivatives have become an increasingly popular form of resistance training among youth athletes over the past decade. This study aimed to examine the loading profiles of youth athletes during the hang power clean to determine optimal loading parameters for force, power, rate of force development, and barbell velocity. Sixteen male youth athletes (Age: $16.94 \pm 0.97$ years; Height: $180.08 \pm 8.14 \mathrm{~cm}$; Body mass: $81.06 \pm 15.04 \mathrm{~kg}$; Hang Clean 1RM $70.17 \pm 14.41 \mathrm{~kg}$ ) performed three repetitions of the hang power clean at $10 \%$ intervals ranging from $30-90 \%$ of their one-repetition maximum (1RM). One-way repeated measures ANONAs revealed that external load had a significant effect on the peak and average of all variables examined $(p<0.05)$. Most notably, peak power was maximized at 70\% 1RM which was not significantly different 60-90\% 1RM. Peak rate of force development was maximized at $90 \% 1 \mathrm{RM}$, though it was not significantly greater than $50-90 \% 1 \mathrm{RM}$. Conversely peak barbell velocity was maximized at 30\% 1RM which was significantly greater than $50-90 \% 1 \mathrm{RM}$. While the results for power are similar to that of older, stronger athletes, the youth population in this study maximized barbell velocity and rate of force development at different external loads compared to more developed athletes. These results seem to suggest that youth athletes need to achieve a higher level of strength before they are capable of training with high relative external loads while maintaining high barbell velocities.
\end{abstract}

Keywords: youth, loading profiles, force-velocity, power, hang power clean

@MJSSMontenegro

HANG CLEAN LOADING PROFILES IN YOUTH ATHLETES

http://mjssm.me/?sekcija=article\&artid=233

Cite this article: Mehls, K.D., Martinez, S.C., Edwards, C. (2022). An Examination of Loading Profiles for Youth Athletes Performing the Hang Power Clean. Montenegrin Journal of Sports Science and Medicine, 11(1), 65-70. https://doi. org/10.26773/mjssm.220308

\section{Introduction}

It is imperative that competitive athletes produce large forces in relatively small timeframes during running, jumping, and cutting tasks (Channel \& Barfield, 2008; McQuilliam et al., 2020; Meylan et al., 2015). To maximize this ability, athletes utilize resistance training exercises that produce maximal force in short time durations, thus enhancing their force-velocity profile (Morrissey et al., 1995). Weightlifting exercises and their derivatives have been advocated as an effective way to enhance the force-velocity profiles of various athletes (Suchomel et al., 2017; Suchomel et al., 2015). However, the force-velocity characteristics of a given training exercise depend on several variables, one of which is external load (Suchomel et al., 2017).

External load is a commonly modified variable in resistance training programs and is partially responsible for dic-

Received: 22 September 2021 | Accepted after revision: 18 January 2022 | Early access publication date: 7 February 2022 | Final publication date: 1 March 2022 (c) 2022 by the author(s). License MSA, Podgorica, Montenegro. This article is an open access article distributed under the terms and conditions of the Creative Commons Attribution (CC BY).

Conflict of interest: None declared. 
tating the location of a specific exercise on the force-velocity curve (Suchomel et al., 2017). Loading profiles provide insight into the athletes' ability to accelerate a given load and achieve high power, barbell velocity, and force outputs (Meylan et al., 2015; Sheppard et al., 2008). The influence external load exhibits over the force-velocity characteristics of a training exercise makes it is necessary to further investigate the loading profiles associated with power, barbell velocity, force, and rate of force development (RFD) (Flores et al., 2007; Soriano et al., 2015). Coaches can use information from loading profiles to determine which external loads maximize one of the aforementioned variables along the force-velocity spectrum for a given exercise.

The hang power clean (HPC), has been widely studied to determine the loading parameters to optimize a variety of force-velocity variables. In professional rugby players, it was found external loads of 90\% 1RM optimized peak force and peak RFD, while lighter external loads of 80\% 1RM and $50 \% 1 \mathrm{RM}$ optimized peak power and peak velocity, respectively (Kilduff et al., 2007). In nonprofessional athletes and recreationally trained men with power clean experience, these numbers seemingly vary where peak power was maximized between $65-80 \%$ of $1 \mathrm{RM}$, peak force between 80 $90 \%$ of 1 RM, peak RFD between $30-60 \%$ of 1 RM, and peak velocity between $30-60 \%$ of $1 \mathrm{RM}$ (Kawamori et al., 2005; Suchomel et al., 2014A; Suchomel et al., 2014B). The wide ranging loading profiles for these studies have been attributed to variation in strength levels and training statuses of the athletes or participants. Several studies have suggested that stronger, more well trained athletes utilize higher relative external loads to maximize these common variables (Angel 1975, Kawamori et al., 2005; Stone et al., 2003), while some have noted that weaker, less trained athletes maximized one or more of these variables at higher relative loads compared to their well-trained counterparts (Baker et al., 2001).

Several studies have advocated for the use of the weightlifting exercises and their derivatives in adolescent populations to train athletes' strength-power characteristics (Channel \& Barfield, 2008; Scherfenber \& Burns, 2013). In fact, many strength coaches regard these lifts as staples of their training programs (Duehring et al., 2009), and resistance training is widely accepted as a safe and effective method for increasing muscular strength and power in adolescent populations (McQuilliam et al., 2020; Myers et al., 2017). Despite this, there has been a lack of investigation regarding the power, force, barbell velocity, and RFD loading profiles for youth athletes. Therefore, the purpose of this study was to examine the loading profiles of peak and mean power, force, barbell velocity, and RFD for youth athletes performing the HPC to determine the optimal loading parameters for these variables.

\section{Methods}

\section{Participants}

A power analysis conducted using $\mathrm{G}^{\star}$ Power (version 3.1.9.7, Kiel, Germany) with an effect size set at 0.3 , an alpha level of 0.05 , and a power of 0.80 determined a minimum number of twelve participants was required for the study (Faul et al., 2007). Sixteen high school male athletes (Age: $16.94 \pm 0.97$ years; Height: $180.08 \pm 8.14 \mathrm{~cm}$; Body mass: $81.06 \pm 15.04 \mathrm{~kg}$; Hang Clean $1 \mathrm{RM} 70.17 \pm 14.41 \mathrm{~kg}$; Relative Strength (HPC 1RM/Body Mass): $0.87 \pm 0.15$ ) were re- cruited from local private high schools to participate in the study. All athletes were required to compete in at least one power-based sport during the school year and had actively engaged in a structured resistance training program under the supervision of a Certified Strength and Conditioning Specialist for at least four weeks prior to testing. Sports represented included American football, tennis, wrestling, basketball, lacrosse, and track and field (sprints and throws). There were several multiport athletes included in the study and all participated in structured resistance training during the school year as part of their school curriculum. Athletes currently participating in a rehabilitation program excluded from participation. All participants and their parents/legal guardians (when necessary) were informed of the benefits and risks of participation and signed an informed consent document as approved by the University's Institutional Review Board.

\section{Procedures}

Participants attended three testing sessions spaced a minimum of 48 hours apart and participants were asked to refrain strenuous exercise 24 hours prior to testing. During the first session body mass was determined using a digital scale (Tanita Worldwide, Model BF 522, Arlington Heights, Illinois) to the nearest $0.1 \mathrm{~kg}$ and height was assessed to the nearest $0.1 \mathrm{~cm}$ using a stadiometer (SECA Corporation, Model 222, Germany). After anthropometric measurements were taken, participants completed a dynamic warmup that consisted of two sets of twenty meters of each of the following: high knees, butt kicks, lunges, high leg kicks, inchworms, and backwards runs. Participants then performed two sets of five repetitions in the HPC at $50 \%$ of their estimated 1RM. From this point 1RM testing continued as described by procedures from the National Strength and Conditioning Association (Haff \& Tripplett, 2016). Athletes were instructed to begin the lift from the mid-thigh position and were allowed to begin with a countermovement in which the bar passed no lower than the top of the knee. For the lift to be counted, the athlete had to perform the catch with the thighs above parallel and stand up to a fully erect position. Athletes were instructed to perform the lift as rapidly as possible.

Testing sessions two and three utilized the same warmup as testing session one, after which all athletes performed 3 consecutive repetitions of the HPC at loads of $30 \%, 60 \%$, and $90 \%$ in testing session two and $40 \%, 50 \%, 70 \%$ and $80 \%$ of their $1 \mathrm{RM}$ in testing session three. These repetitions were performed in a consecutive fashion to mimic a typical weightlifting training session and two testing sessions were used to help mitigate any cumulative fatigue that may have occurred while performing seven sets of a HPC. Loads were tested in a random counterbalanced order and four minutes of rest was provided between each tested load.

\section{Data Analysis}

A TENDO Unit (Model V-620, Tendo Sports Machines, Slovak Republic) linear position transducer was attached at the center of the barbell to record barbell displacement data. A movement filter of $35 \mathrm{~cm}$ was applied to the microcomputer to ensure only relevant movement data was captured, as recommended by TENDO Sport. The TENDO unit contains a microcomputer connected to a laptop which propa- 
gates the raw barbell displacement data via the TENDO unit computer software. From the recorded barbell displacement data velocity, force, and power are estimated. Peak and mean power, velocity, force, and RFD for each repetition was calculated using the mass of the barbell only (Flores et al., 2007, Hori et al., 2006). All variables were automatically calculated from barbell displacement via the TENDO unit software except for instantaneous RFD which was calculated by dividing change in force by change in time.

\section{Statistical Analysis}

For mean and peak power, velocity, force, and RFD the average of the three performed repetitions was used for statistical analysis. Eight separate one-way repeated-measures ANOVAs with relative load as the within subject factor $(30 \%, 40 \%, 50 \%, 60 \%, 70 \%, 80 \%, 90 \% 1 \mathrm{RM})$ were conducted for peak and mean power, velocity, force, and RFD. Effect sizes were calculated using partial eta squared $\left(\eta p^{2}\right)$ for overall ANOVAs. Post hoc comparisons were conducted using a Bonferroni correction and effect sizes were calculated between the load which optimized the variable and all other loads using Hedges' g. Greenhous-Geisser adjustment was applied when sphericity was violated and an alpha level was set at .05 for all statistical procedures.

\section{Results}

Velocity

External load has a significant main effect on both average $\left(\mathrm{F}(2.92,43.79)=27.09, \mathrm{p}<0.001, \eta \mathrm{p}^{2}=0.64\right)$ and peak $\left(\mathrm{F}(2.94,44.09)=29.62, \mathrm{p}<0.001, \eta \mathrm{p}^{2}=0.64\right)$ velocity. An external load of $30 \% 1 \mathrm{RM}$ produced the greatest average velocity which was significantly greater than 50\%, 60\%, 70\%, $80 \%$ and $90 \%$ of $1 \mathrm{RM}(\mathrm{p}<0.05, \mathrm{~g}=0.83,1.17,1.21,1.65$, 1.93 ) but was not $40 \% 1 \mathrm{RM}(\mathrm{p}>0.05, \mathrm{~g}=0.47)$. The greatest peak velocity occurred at $30 \% 1 \mathrm{RM}$ which was greater than $50 \%, 60 \%, 70 \%, 80 \%$ and $90 \%$ of $1 \mathrm{RM}(\mathrm{p}<0.05, \mathrm{~g}=0.87$, $1.13,1.30,1.67,2.00)$ but not $40 \% 1 \mathrm{RM}(\mathrm{p}>0.05, \mathrm{~g}=0.47)$.

\section{Force}

External load had a significant effect on both average $\left(\mathrm{F}(1.25,18.79)=307.41, \mathrm{p}<0.001, \eta \mathrm{p}^{2}=0.95\right)$ and peak $\left(\mathrm{F}(2.82,42.35)=111.83, \mathrm{p}<0.001, \eta \mathrm{p}^{2}=0.88\right)$ force. An external load of $90 \% 1 \mathrm{RM}$ produced the greatest average force which was significantly greater than $30 \%, 40 \%, 50 \%, 60 \%$, $70 \%$, and $80 \%$ of $1 \mathrm{RM}(\mathrm{p}<0.05, \mathrm{~g}=4.04,3.20,2.40,1.76,1.07$, 0.59 ). The greatest peak force also occurred at $90 \% 1 \mathrm{RM}$ which was significantly greater than $30 \%, 40 \%, 50 \%, 60 \%, 70 \%$, and $80 \% 1 \mathrm{RM}(\mathrm{p}<0.05, \mathrm{~g}=2.82,1.93,1.41,1.13,0.42,0.26)$.

\section{Power}

External load had a significant effect on average $(\mathrm{F}(2.77,41.52)$ $\left.=99.51, \mathrm{p}<0.001, \eta \mathrm{p}^{2}=0.87\right)$ and peak $(\mathrm{F}(2.32,34.75)=33.90, \mathrm{p}$ $\left.<0.001, \eta \mathrm{p}^{2}=0.69\right)$ power. Average power was maximized at an external load of $90 \% 1 \mathrm{RM}$ which was greater than $30 \%, 40 \%, 50 \%$, $60 \%$, and $80 \%$ of $1 \mathrm{RM}(\mathrm{p}<0.05, \mathrm{~g}=2.20,1.73,1.22,0.88,0.27)$, but not 70\% 1RM ( $\mathrm{p}>0.05, \mathrm{~g}=0.35)$. Peak power was maximized at $70 \% 1 \mathrm{RM}$ which was significantly greater than $30 \%, 40 \%$, and $50 \% 1 \mathrm{RM}(\mathrm{p}<0.05, \mathrm{~g}=1.28,0.91,0.63)$ but not than $60 \%, 80 \%$, and $90 \%$ of $1 \mathrm{RM}$ ( $\mathrm{p}>0.05, \mathrm{~g}=0.48,0.03,0.01)$.

\section{Rate of Force Development}

Finally, external load had a significant effect on average $\left(\mathrm{F}(3.10,46.54)=8.42, \mathrm{p}<0.001, \eta \mathrm{p}^{2}=0.36\right)$ and peak $\left(\mathrm{F}(2.28,34.19)=3.57, \mathrm{p}=0.034, \eta \mathrm{p}^{2}=0.19\right)$ RFD. An external load of 70\% $1 \mathrm{RM}$ produced the greatest average RFD which was significantly greater than $30 \%$ and $40 \% 1 \mathrm{RM}(\mathrm{p}$ $<0.05, \mathrm{~g}=1.05,0.71)$ but not than $50 \%, 60 \%, 80 \%$, and $90 \%$ of 1RM ( $\mathrm{p}>0.05, \mathrm{~g}=0.49,0.32,0.17,0.01)$. The greatest peak RFD occurred at 90\% 1RM which was greater than $30 \%$ and $40 \%$ of $1 \mathrm{RM}(\mathrm{p}<0.05, \mathrm{~g}=0.99,0.93)$, but not than $50 \%, 60 \%, 70 \%$, and $80 \% 1 \mathrm{RM}$ (p > 0.05, $\mathrm{g}=0.66$, $0.14,0.25,0.33$ ). Results from pairwise comparisons can be found in Figure 1 while means and standard deviations for all external loads across all measure variables can be found in Table 1.

Table 1. Mean and Peak Barbell Velocity, Force, Power, and Rate of Force Development across Training Loads

\begin{tabular}{cccccccc}
\hline \multirow{2}{*}{ Variables } & \multicolumn{7}{c}{ Load } \\
\cline { 2 - 7 } & $30 \% 1 \mathrm{RM}$ & $40 \% 1 \mathrm{RM}$ & $50 \% 1 \mathrm{RM}$ & $60 \% 1 \mathrm{RM}$ & $70 \% 1 \mathrm{RM}$ & $80 \% 1 \mathrm{RM}$ & $90 \% 1 \mathrm{RM}$ \\
\hline Peak Velocity (m/s) & $2.30 \pm 0.38$ & $2.15 \pm 0.26$ & $2.03 \pm 0.21$ & $1.93 \pm 0.26$ & $1.92 \pm 0.16$ & $1.81 \pm 0.15$ & $1.70 \pm 0.18$ \\
Mean Velocity (m/s) & $1.69 \pm 0.31$ & $1.56 \pm 0.22$ & $1.47 \pm 0.19$ & $1.37 \pm 0.21$ & $1.39 \pm 0.14$ & $1.29 \pm 0.12$ & $1.21 \pm 0.13$ \\
Peak Force (N) & $580 \pm 195$ & $729 \pm 268$ & $886 \pm 253$ & $937 \pm 291$ & $1133 \pm 337$ & $1189 \pm 290$ & $1265 \pm 272$ \\
Mean Force (N) & $223 \pm 46$ & $289 \pm 69$ & $371 \pm 78$ & $431 \pm 95$ & $502 \pm 119$ & $565 \pm 120$ & $643 \pm 136$ \\
Peak Power (W) & $909 \pm 418$ & $1074 \pm 450$ & $1230 \pm 400$ & $1282 \pm 465$ & $1526 \pm 517$ & $1514 \pm 387$ & $1520 \pm 394$ \\
Mean Power (W) & $387 \pm 136$ & $464 \pm 153$ & $556 \pm 168$ & $610 \pm 207$ & $721 \pm 231$ & $745 \pm 205$ & $804 \pm 224$ \\
Peak RFD (N/s) & $7061 \pm 3644$ & $8192 \pm 4535$ & $9756 \pm 4703$ & $12239 \pm 13110$ & $11982 \pm 6805$ & $11518 \pm 5969$ & $13698 \pm 6780$ \\
Mean RFD (N/s) & $2431 \pm 952$ & $2930 \pm 1271$ & $3355 \pm 1200$ & $3528 \pm 2158$ & $4233 \pm 2171$ & $3915 \pm 1389$ & $4212 \pm 1376$ \\
\hline
\end{tabular}

Note. $\mathrm{m} / \mathrm{s}=$ Meters per second, $\mathrm{N}=$ Newtons, $\mathrm{W}=$ Watts, RFD = Rate of Force Development; N/s = Newtons per second: 1 RM = 1 Repetition Maximum

\section{Discussion}

This study examined average and peak force, barbell velocity, power, and RFD loading profiles in high school male athletes performing the HPC. The current study saw that external load had a significant effect on peak power which was greatest at 70\% 1RM and significantly greater than 30-50\% 1RM. Additionally, average power was maximized at an external load of $90 \% 1 \mathrm{RM}$ which was which was significantly greater than 30 $60 \% 1 \mathrm{RM}$ and $80 \% 1 \mathrm{RM}$, but not $70 \% 1 \mathrm{RM}$. These findings in- dicate that when training to maximize power output in youth, male athletes, external load prescriptions between $70-90 \%$ of $1 \mathrm{RM}$ are optimal.

These results are comparable to the results seen in older, stronger athletes. In two separate groups of trained college males (hang clean 1RM: $104.89 \pm 15.10 \mathrm{~kg} ; 111.12 \pm 20.40$ $\mathrm{kg}$ ), peak power was maximized at $65 \%$ and $80 \% 1 \mathrm{RM}$, though these were not significantly different from other loads tested in the respective studies (Suchomel et al., 2014A; Suchomel et 

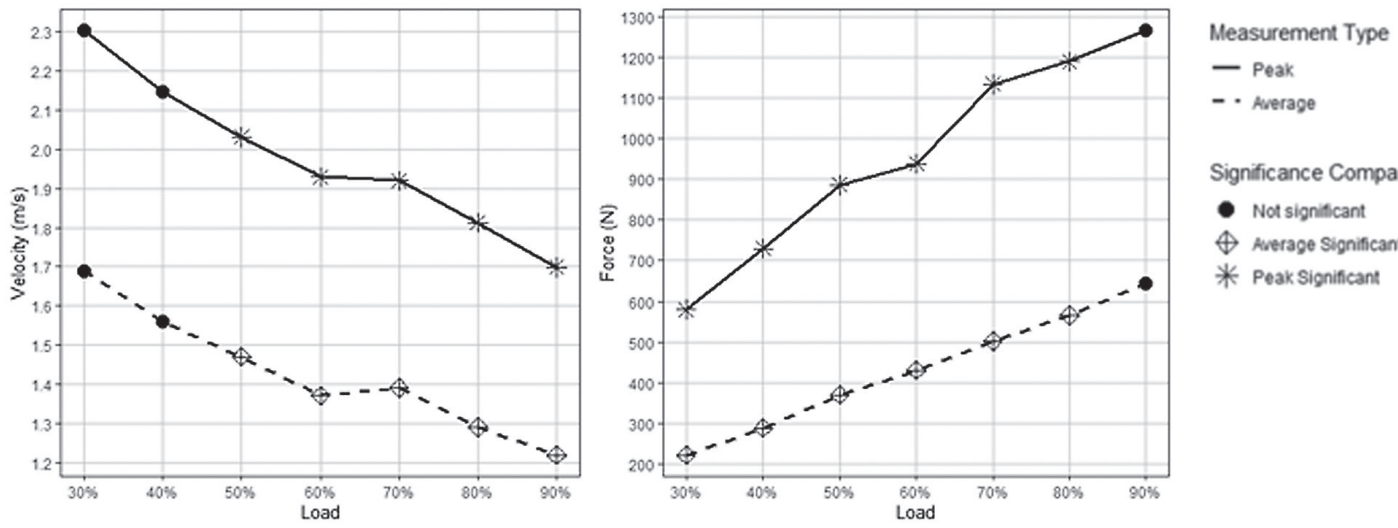

- Peak

Significance Compared to Largest Value

- Not significant

$\oplus$ Average Significant

* Peak Significant
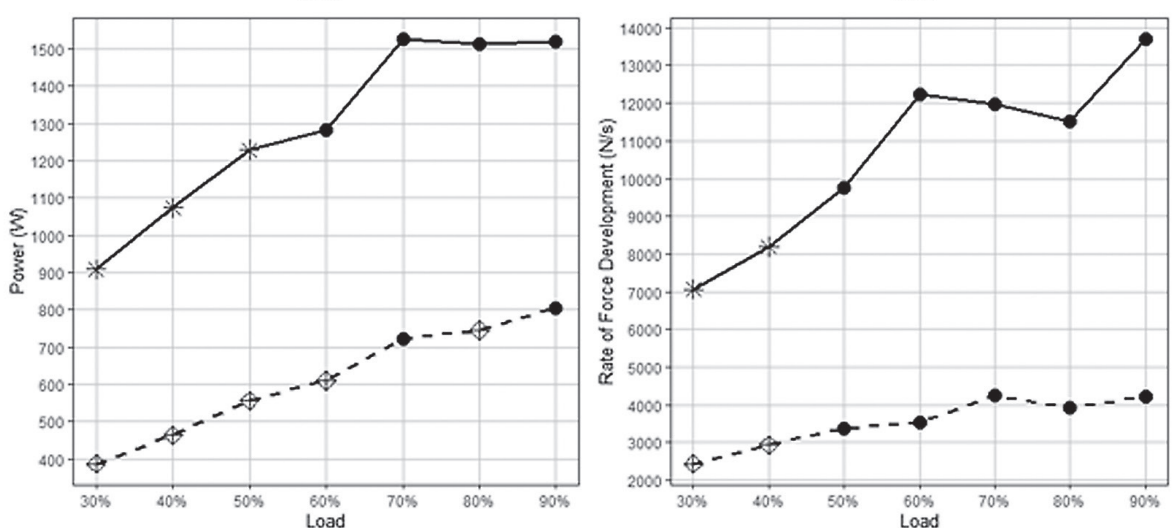

Figure 1. Changes in peak and average power, force, velocity, and rate of force development across loads. Note. $\mathrm{m} / \mathrm{s}=$ meters per second; $\mathrm{N}=$ Newtons; $\mathrm{W}=$ Watts; $\mathrm{N} / \mathrm{s}=$ Newtons per second

al., 2014B). Similarly, Kilduff et al (2007) found that in professional rugby players (HPC 1RM: $107 \pm 13 \mathrm{~kg}$ ) peak power was maximized at $80 \% 1 \mathrm{RM}$ which was significantly greater than 30 and $40 \% 1 \mathrm{RM}$. Similar results were seen in colligate weightlifters (hang clean 1RM: $107 \pm 18.8 \mathrm{kgs}$ ) who maximized both peak and average power at $70 \%$ of $1 \mathrm{RM}$ which was significantly greater than 30 and $40 \% 1 \mathrm{RM}$. Combined with the present study results, it would appear that external loads between $65-$ $80 \% 1 \mathrm{RM}$ are capable of maximizing power production in a wide variety of athletes independent of strength level.

The youth athletes tested in this study produced their greatest peak and average forces at $90 \%$ of $1 \mathrm{RM}$, which is congruent with other research examining force output during the HPC in different populations (Kilduff et al., 2007; Suchomel et al., 2014A; Suchomel et al., 2014B). As 90\% 1RM was the greatest external load in this study, it is logical that this load produced the greatest force. However, when examining barbell velocity, the youth athletes in this study maximized their peak and average barbell velocity at $30 \% 1 \mathrm{RM}$ which was significantly greater than $50-90 \% 1 \mathrm{RM}$. These results are contradictory to other studies which examined barbell velocity in stronger athletes where barbell velocity was maximized between $45-60 \%$ $1 \mathrm{RM}$. Only one of these studies noted a significant effect of external load on barbell velocity, and all lacked any general trend where velocity decreased as load increased (Kawamor et al., 2005; Kilduff et al., 2007; Suchomel et al., 2014A; Suchomel et al., 2014B). Examining all of these results together, it would appear that stronger athletes are more capable of maintaining higher barbell velocities at heavier loads while weaker athletes need lighter loads to produce maximal barbell velocity.

Rate of force development is a widely evaluated characteristic of explosive athletes because it indicates an athlete's abil- ity to produce high forces at high velocities (Maffiuletti et al., 2016). Maximizing RFD requires the optimal interplay of barbell velocity and force production, despite the fact that maximal barbell velocity often occurs at low external loads while maximal force production requires high external loads. It has been suggested that to increase a person's RFD, it is necessary to train with high movement velocities (Blazevich et al., 2020). However, recent studies have indicated that stronger athletes have greater success enhancing their force-velocity profiles through weightlifting and plyometric training than their weaker counterparts (James et al., 2018; James et al., 2020). As it has been shown stronger athletes are capable of maintaining barbell velocities across a wide range of relative external loads (Kilduff et al., 2007; Suchomel et al., 2014A; Suchomel et al., 2014B), it is a logical extension that these athletes may obtain the benefits of heavy training at high velocities. Conversely, the less developed youth athletes in this study required a lighter external load to maximize barbell velocity which decreased as load increased. With the popularization of weightlifting exercises to enhance athletic performance in youth population, this makes for an interesting paradigm when examining optimal loading parameters for younger athletes.

The present study saw both peak and average RFD maximized at 90\% 1RM which was significantly greater than 30 and 40\% 1RM. These RFD results are similar to those seen in professional rugby players where peak RFD occurred at $90 \%$ $1 \mathrm{RM}$, though this was not significantly greater than the other external loads tested (Kilduff et al., 2007). However, collegiate weightlifters have been shown to maximize peak RFD at a lower relative intensity of $60 \% 1 \mathrm{RM}$, but again this was not significantly greater than any other loads tested (Kawamori et al., 2005). The lack of significant differences seen in both these 
studies suggests that stronger athletes may be capable of maximizing RFD across various loads in the same way they are capable of maintaining barbell velocity across loads. Conversely, the weaker athletes in the present study seem to require relatively heavy loads to maximize RFD, indicating the primary factor in developing RFD in weaker athletes is maximal force production. This implies that when developing young athletes, it may be necessary to first place emphasis on maximal force development prior to training to enhance the force-velocity profiles of youth athletes.

One potential limitation to this study was the use of a linear transducer device which is not capable of distinguishing horizontal from vertical displacement of the barbell and can in some instances overestimate power. Future studies should examine this population utilizing force plate technology combined with a linear transducer to present the most accurate force, power, RFD, and velocity data for youth athletes performing weightlifting variations.

\section{Conclusion}

The present study examined several force-velocity qualities in youth athletes who maximized peak power at $70 \%$ of $1 \mathrm{RM}$, which is congruent with similar studies in different populations suggesting that loads of $65-80 \% 1 \mathrm{RM}$ are optimal for maximizing power in most athletes. The present study saw barbell velocity maximized at $30-40 \% 1$ RM while RFD was maximized at $90 \%$ of $1 \mathrm{RM}$. These results differ from stronger athletes, suggesting the ability to produce maximal force heavily influences youth athletes' ability to maximize RFD. Athletes are trained under a variety of systems which seek to maximize the athletes' potential and often focuses on specific strength qualities during training blocks or training sessions. When optimizing the RFD is the primary objective of a training session, strength level and developmental phase of the athlete should be considered when prescribing external load. For coaches working with youth athletes, it may be necessary to introduce heavy strength training to increase the athletes' overall strength levels and maximize muscular strength adaptations prior to being concerned with enhancing barbell velocity. Future studies may work to establish cut points that will help coaches and practitioners know when athletes have gained enough maximal strength to make maximal velocity training a more valuable component of training.

\section{References}

Angel, R. W. (1975). Myoelectric patterns associated with ballistic movement: Effect of unexpected changes in load. Journal of Human Movement Studies, 1(2), 96-103.

Baker, D., Nance, S., \& Moore, M. (2001). The load that maximizes the average mechanical power output during jump squats in power-trained athletes. Journal of Strength and Conditioning Research, 15(1), 92-97.

Blazevich, A. J., Wilson, C. J., Alcaraz, P. E., \& Rubio-Arias, J. A. (2020). Effects of resistance training movement pattern and velocity on isometric muscular rate of force development: a systematic review with meta-analysis and meta-regression. Sports Medicine, 50(5), 943-963. https:// doi.org/10.1007/s40279-019-01239-x

Channell, B. T., \& Barfield, J. P. (2008). Effect of Olympic and traditional resistance training on vertical jump improvement in high school boys. The Journal of Strength \& Conditioning Research, 22(5), 1522-1527. https://doi.
org/10.1519/JSC.0b013e318181a3d

Duehring, M. D., Feldmann, C. R., \& Ebben, W. P. (2009). Strength and conditioning practices of United States high school strength and conditioning coaches. The Journal of Strength \& Conditioning Research, 23(8), 2188-2203. https://doi.org/10.1519/JSC.0b013e3181bac62d

Faul, F., Erdfelder, E., Lang, A. G., \& Buchner, A. (2007). G* Power 3: A flexible statistical power analysis program for the social, behavioral, and biomedical sciences. Behavior Research Methods, 39(2), 175-191. https://doi.org/10.3758/ bf03193146

Flores, F. J., Sedano, S., \& Redondo, J. C. (2017). Optimal load and power spectrum during snatch and clean: differences between international and national weightlifters. International Journal of Performance Analysis in Sport, 17(4), 521-533. https://doi.org/10.1080/24748668 .2017 .1366758

Haff, G., \& Triplett, N. T. (2016). Essentials of strength training and conditioning. Fourth edition. Champaign, IL: Human Kinetics.

Hori, N., Newton, R. U., Andrews, W. A., Kawamori, N., McGuigan, M. R., \& Nosaka, K. (2008). Does performance of hang power clean differentiate performance of jumping, sprinting, and changing of direction? The Journal of Strength \& Conditioning Research, 22(2), 412-418.

Hori, N., Newton, R. U., Nosaka, K., \& McGuigan, M. R. (2006). Comparison of different methods of determining power output in weightlifting exercises. Strength and Conditioning Journal, 28(2), 34. https://doi.org/10.1519/ JSC.0b013e318166052b

James, L. P., Gregory Haff, G., Kelly, V. G., Connick, M. J., Hoffman, B. W., \& Beckman, E. M. (2018). The impact of strength level on adaptations to combined weightlifting, plyometric, and ballistic training. Scandinavian Journal of Medicine \& Science in Sports, 28(5), 1494-1505. https://doi. org/10.1111/sms.13045

James, L. P., Suchomel, T. J., Comfort, P., Haff, G. G., \& Connick, M. J. (2020). Rate of Force Development Adaptations after Weightlifting-Style Training: The Influence of Power Clean Ability. The Journal of Strength \& Conditioning Research, 33(11):2936-2944. https://doi.org/10.1519/ JSC.0000000000002534

Kawamori, N., Crum, A. J., Blumert, P. A., Kulik, J. R., Childers, J. T., Wood, J. A., ... \& Haff, G. G. (2005). Influence of Different Relative Intensities on Power Output During the Hang Power Clean: Identification of the Optimal Load. Journal of Strength and Conditioning Research, 19(3), 698-708. https://doi.org/10.1519/16044.1

Kilduff, L. P., Bevan, H., Owen, N., Kingsley, M. I., Bunce, P., Bennett, M., \& Cunningham, D. (2007). Optimal loading for peak power output during the hang power clean in professional rugby players. International Journal of Sports Physiology and Performance, 2(3), 260-269. https://doi. org/10.1123/ijspp.2.3.260

Maffiuletti, N. A., Aagaard, P., Blazevich, A. J., Folland, J., Tillin, N., \& Duchateau, J. (2016). Rate of force development: physiological and methodological considerations. European Journal of Applied Physiology, 116(6), 1091-1116. https://doi.org/10.1007/ s00421-016-3346-6

McQuilliam, S. J., Clark, D. R., Erskine, R. M., \& Brownlee, T. E. (2020). Free-Weight Resistance Training in Youth 
Athletes: A Narrative Review. Sports Medicine, 1-14. https://doi.org/10.1007/s40279-020-01307-7

Meylan, C. M., Cronin, J. B., Oliver, J. L., Hughes, M. M., Jidovtseff, B., \& Pinder, S. (2015). The reliability of isoinertial force-velocity-power profiling and maximal strength assessment in youth. Sports biomechanics, 14(1), 68-80. https://doi.org/10.1080/14763141.2014.982696

Morrissey, M. C., Harman, E. A., \& Johnson, M. J. (1995). Resistance training modes: specificity and effectiveness. Medicine and Science in Sports and Exercise, 27(5), 648-660.

Myers, A. M., Beam, N. W., \& Fakhoury, J. D. (2017). Resistance training for children and adolescents. Translational Pediatrics, 6(3), 137. https://doi.org/10.1542/peds.20201011

Scherfenberg, E., \& Burns, S. (2013). Implementing Hang Cleans for the Improvement of Vertical Jump in High School Athletes. Journal of Exercise Physiology Online, 16(2).

Sheppard, J. M., Cormack, S., Taylor, K. L., McGuigan, M. R., \& Newton, R. U. (2008). Assessing the force-velocity characteristics of the leg extensors in well-trained athletes: The incremental load power profile. The Journal of Strength \& Conditioning Research, 22(4), 1320-1326. https://doi. org/10.1519/JSC.0b013e31816d671b

Soriano, M. A., Jiménez-Reyes, P., Rhea, M. R., \& Marín, P. J. (2015). The optimal load for maximal power production during lower-body resistance exercises: a metaanalysis. Sports Medicine, 45(8), 1191-1205. https://doi. org/10.1007/s40279-015-0341-8

Stone, M. H., O'Bryant, H. S., McCoy, L., Coglianese, R., Lehmkuhl, M., \& Schilling, B. (2003). Power and maximum strength relationships during performance of dynamic and static weighted jumps. Journal of Strength and Conditioning Research, 17(1), 140-147. https://doi. org/10.1519/1533-4287(2003)017<0140:pamsrd >2.0.co;2

Suchomel, T. J., Beckham, G. K., \& Wright, G. A. (2014a). The impact of load on lower body performance variables during the hang power clean. Sports Biomechanics, 13(1), 87-95. https://doi.org/10.1080/14763141.2013.861012

Suchomel, T. J., Comfort, P., \& Lake, J. P. (2017). Enhancing the force-velocity profile of athletes using weightlifting derivatives. Strength \& Conditioning Journal, 39(1), 10-20. https://doi.org/10.1519/SSC.0000000000000275

Suchomel, T. J., Comfort, P., \& Stone, M.H. (2015). Weightlifting pulling derivatives: Rationale for implementation and application. Sports Medicine, 45(6), 823-839. https:/doi. org/10.1007/s40279-015-0314-y

Suchomel, T. J., Wright, G. A., Kernozek, T. W., \& Kline, D. E. (2014b). Kinetic comparison of the power development between power clean variations. The Journal of Strength \& Conditioning Research, 28(2), 350-360. https://doi. org/10.1519/JSC.0b013e31829a36a3 